\title{
Developing High Performance Teachers in 21Century Schools: A Case Study of Beliefs and Behaviours of Master Teachers
}

\author{
Wendy Barber \\ University of Ontario Institute of Technology, Canada
}

\begin{abstract}
The purpose of this paper is to examine four case studies of teachers who have demonstrated excellence in their teaching practice. Orlick [10], has identified seven characteristics that are present in high performing individuals. These include commitment, belief, full focus, positive images, mental readiness, distraction control and constructive evaluation. The author posits that master teachers hold similar beliefs and exhibit behaviours that are common among high performers across professions, thus enabling them to excel in their professional practice. The challenge of creating educational cultures of excellence in schools is complex and interweaves many critical factors. In spheres beyond the teacher development literature, the notion of excellence includes consideration not only of the individual actions that represent excellence in teaching, but also the beliefs and behaviours that foster or provide opportunities for growth in this direction. Unless the conditions for excellence to occur are present, this quality may remain inert. This case study summarizes the beliefs and behaviours of four master teachers in an urban secondary school in the Greater Toronto area, and has implications for teacher development and pre-service teachers.
\end{abstract}

\section{Introduction}

Orlick and colleagues [11] reveal there are several common methods used by performers in the fields of music, athletics, medicine, astrophysics, and coaching. Initially, Orlick proposed a model of excellence that was based primarily on a study of high-performance athletes. He identified seven common mental skills in the Wheel of Excellence used by human beings in the pursuit of excellence: "commitment, belief, full focus, positive images, mental readiness, distraction control and constructive evaluation". These constructs may form a strong theoretical basis for a review of teacher excellence. Orlick's further studies of musicians elaborated on this model to include an abiding love for and enjoyment of the profession, specific performance goals, and a strong sense of self. In addition, Talbot and Orlick's [18] later study examined internationally renowned musical soloists. Participants were identified by specific performance criteria, were interviewed and the transcripts of these discussions were analyzed qualitatively. This work found that the mental skills of top classical musicians are common in comparison to each other, and it also revealed that high-level performers refer to "creativity, flexibility, and spontaneity as critical components of excellent performance". The field of medicine also provides examples of how professionals are trained with a view of excellent performance in mind. Tribble and Newburg [19] discuss a system of education for young physicians wherein candidates are indoctrinated as virtual beginners but achieve a level of mastery in a relatively short period of time. They discuss a cross-training approach that includes "preparation, leadership, awareness, decisionmaking, reflection, vision and flow". Barbour and Orlick [2] studied elite-level National Hockey League players and have identified four major factors contributing to their success. These included "desire or determination, self-sacrifice or being a team player, the ability to cope well with pressure or maturity, and coachability or dependability". Finally, Orlick's [10] in depth interviews with Canadian astronauts Chris Hadfield and Marc Garneau have produced similar comments on the qualities required to generate excellent performance. In addition to the characteristics noted by other high performers, Orlick also included "the ability to prioritize, think and act clearly under stress, to maintain a big picture focus and to quickly rebound from failure and move on the next task".

\section{Methodology}

The case study method was chosen for this research for many reasons. The following operational definition from Merriam [8] states that a qualitative case study is an intensive, holistic description and 
analysis of a single instance, phenomenon or social unit. I can 'fence in' what I am going to study. The case then, could be a person such as a student, teacher, principal; a program, a school, a community and so on.

In addition, Merriam [8] reiterates that a case study is particular (in this research the focus was on teacher excellence and particular teachers and schools), descriptive (this research focused on teachers' stories about excellence) and heuristic (this research broadened the researcher's understanding of notions of excellence). The descriptions used in this research were "holistic, lifelike, grounded and exploratory, using prose and literary techniques to describe, elicit images and analyse situations" [8]. Because of the low level of control that the researcher had over the events studied, the case study was a good choice of methodology. In addition, because the researcher had operationally defined excellence as an inclusive process, as opposed to a measurable final end point, the case study was an appropriate methodology. Merriam [8] states that this was so because the "case study is a particularly suitable design if you are interested in process". In this research, four teacher case studies were examined to identify the personal and professional ways that physical education teachers and coaches become high performers. The advantage of using multiple cases was that the potential for generalizability was increased and the external validity was enhanced.

The study design and sample selection for this research were based on principles of qualitative case study work. Merriam [8] refers to two types of sampling which are probability (random) and nonprobability (purposeful) sampling. Since the goal for this research was not to generate numerical or statistical results, nonprobability sampling was the method of choice for this research. The sample of teachers to be studied had been selected purposefully; therefore, the method used can be referred to as purposive, nonprobability sampling. This method was ideal for studying teacher excellence, since selection criteria were determined by Orlick's [10] model of the Wheel of Excellence. Teachers who demonstrated all or most of the seven characteristics, as chosen by their principal and the researcher, were selected to do the individual interviews and questionnaires. As such, the sample was also criterion based, and used Orlick's [10] criteria for high performers. This type of sample can be referred to as unique, since all individuals performed at high levels. Merriam [8] states that "a unique sample is based on unique, atypical, perhaps rare attributes or occurrences of the phenomenon of interest. You are interested in them because they are unique or atypical". Finally, the bounded system that is the unit of investigation was that all four teacher cases were taken from the same independent school. This set parameters for analysis of factors in the school environment that contributed to excellence. Four physical education teachers and coaches were participants and completed the school environment questionnaire and provided data, which was analysed based on Cibulka and Nakayama's Characteristics of High-Performing Schools [4].

\subsection{Selection of Teacher Coach Participants}

Four secondary school educators (two male, two female) who acted as both teachers and coaches in their formal professional duties at the senior school level were participants in the study. Each of these individuals had attained a high level of achievement in his/her profession. Participants had been identified by the principal and the researcher as having attained a high level of excellence in teaching and coaching. Indicators of excellence were defined in the frame of reference identified by the researcher. This frame of reference for individual excellence followed the criteria for excellence stated above, from the research of Orlick [10]. In line with this study, teachers who were identified as excellent demonstrated evidence of at least five of these seven characteristics: commitment, belief in themselves, a positive mental approach, full focus, good distraction control, constructive evaluation and a high level of mental readiness. The author hypothesized that there would emerge several common beliefs and behaviours, and professional and personal practices that could be seen as contributing to excellence in the subjects' teaching development.

All teacher/coaches in this study worked at the same independent school. While there is no governing board for independent school districts, the school in question was part of the provincial and national associations for independent schools and met the required standards to be a member of the organization. The school was also certified by CESI (Canadian Educational Standards Institute) and followed the Ontario Ministry of Education curriculum guidelines. The school site also has a mandatory physical education and extra-curricular athletic program for all students in each term throughout secondary school. In addition, the high percentage of $\mathrm{PhD}$ and master's degree qualified teachers indicates a school which valued professional development, and the Head of school had approved studies in action research in the school.

\subsection{Research Procedures}

The study consisted of three phases. Each phase identified different areas of perception about 
professional excellence. Details regarding the purpose of the phase, the participants' and researcher's responsibilities, and the summary of resulting ideas were included.

2.2.1. Phase 1 Pilot Study. This phase involved two 70 point questionnaires based on Cibulka and Nakayama's [4] work on high-performing organizations and Orlick's [10] work on highperforming individuals. The purpose of the pilot study was to refine and revise both of the questionnaires as research tools, and to clarify any inconsistencies in interpretation of the questions. The school environment questionnaire was given to four teachers in an independent school that had a similar demographic population both in staff and students to the study school. In addition, the individual teacher questionnaire was given to two randomly chosen teachers who did not participate in the overall survey. This enabled the researcher to refine and revise the individual teacher and school environment questionnaires and to clarify teachers' perceptions of each question.

2.2.2. Phase 2 Questionnaires.This phase began with the completion of the 70 point school environment questionnaire by the four study participants in the study group. A general analysis of the participants' perceptions of the school's contributions to excellent teacher performance was included. The school environment questionnaire was designed based on Cibulka and Nakayama's [4] model of high-performing schools and Anderson and Piran's [1] model of health promoting schools. This phase also involved a 70 point individual performance questionnaire that each of the four teacher/coach participants answered. The individual questions were devised based on a review of literature on teacher excellence, mentoring, stress and burnout, and excellence in teaching. These themes were addressed throughout the questionnaire. Answers were rated based on a one to five rating scale, and participants had an opportunity to add anecdotal comments.

Questions were designed to determine the participants' general self-perceptions, and their values and beliefs about excellent teacher/coach performance. The questionnaire also assessed teachers'/coaches' values and perceptions of the role of the healthy school in supporting their striving for professional excellence.
2.2.3. Phase 3 Interviews. This phase involved individual interviews with anecdotal responses to questions which elaborated on the individual's answers to the questionnaire. For example, the questionnaire asked whether the teacher had a significant mentor. During the interview, this was expanded to the question "Can you describe the overall effects which your mentor had on your approaches to excellence". All interviews were audio taped and transcribed by the researcher. Transcriptions of interviews were reviewed in writing by participants in order to clarify comments or questions.

Transcriptions were kept in a locked cabinet for confidentiality, with access by the researcher and her advisor only. Discussion was guided by the researcher on the basis of the themes emerging from the questionnaire. These themes included the teacher's personal philosophy of excellence, the presence of a mentor, meaningful affiliation with and influence of colleagues, the role of the school leader in generating an environment which nurtures excellence, and the relationship between teacher burnout and the pursuit of excellence.

Additional themes which were critical components of this research were discussed. These included the teachers' beliefs and behaviours that they perceived were required for the achievement of excellent teacher performance. Examples of this were a passion for teaching and learning, a high level of professional commitment, and the belief that one is making a real difference in the lives of students. In addition, individual and organizational barriers to high performance were discussed. For instance, teacher timetables, schedules and extracurricular expectations which impacted on a teacher's time emerged as barriers to high achievement. In addition, a non-supportive school leader or the lacks of meaningful interaction with colleagues were discussed as common barriers to high performance in teaching.

2.2.4. Phase 3 Field Observations.Further to this, the researcher arranged to spend one to two hours as an observer in the teacher's/coach's classroom and practice environment. This field observation for each individual participant was placed in the context that was already developed during the questionnaires and interviews. Teachers chose the type of class to be observed based on what they felt would be a demonstration of their professional practice at their best teaching level. Preliminary analysis of the data collected during interviews and questionnaires was done prior to the classroom visits, and recorded in a set of field notes accessible to the researcher only. 
This prepared the researcher to record field observations in the context of the teacher's stated perceptions of the elements required for excellent teaching and coaching. It was clear that an individual teacher's perception of "excellent teaching" was a direct result of the values, beliefs and behaviours which they held in high esteem. As a result, the observation of each participant was placed in this personal context. Each participant had expressed several key values and beliefs about excellent teaching, and these were noted prior to the field observations. The field notes taken during this process were examined to determine the level of congruency between the teacher's actions in the classroom and their responses already recorded. The researcher then analysed if the observed teacher's behaviours reflected the beliefs they had already expressed in both the questionnaire and the interview. A short review of the field observation was discussed with each participant to determine their own perceptions of whether or not that particular lesson was an indicator of their average level of teaching excellence. In this way, the data were effectively triangulated to give a complete, concise picture of excellent teaching as it existed through the actions of the practitioner.

\section{Data Collection and Analysis}

Data were recorded using field notes, and interviews with individual teachers were taped and transcribed for later analysis. These transcripts were provided to each teacher for clarification and adjustment, to ensure that the teacher's comments during both the interview and the class observation were accurate and in the proper context as originally intended by the subject. All transcripts and participant consent forms were stored in a locked space by the researcher and these were stored for one year after the study had been completed. The names, descriptions of extracurricular activities and personal backgrounds of participants and school names used in the analysis were indicated in this report as pseudonyms.

The participants were told on the consent forms that they could request a copy of the final study upon completion. The headmaster was contacted for both permission to perform the study and for anecdotal input about the specific teacher's and coach's performance. The headmaster was also key in subject selection, and he approved the selection of all four participants based on their having exhibited at least five of Orlick's [10] seven characteristics of highperforming individuals. This input was gathered through personal interviews and recorded verbatim using field notes. Formal ethical approval for this study was granted by the Education Research Ethics Board of the University of Toronto prior to data collection.

\section{Findings}

Orlick's Wheel of Excellence [10] can be used to ascertain how high-performing teachers have similarities to excellent performers in other disciplines. Individually, the teachers in the study exhibited common traits according to this theoretical model. In addition to the data revealed by the crosscase analysis, several other critical psychological constructs emerged that appear to play an essential role in teacher excellence. These additional qualities that the teachers in this study exhibited may be specific to performers in educational settings. Despite very different levels of experience, these teachers all possessed these additional characteristics, which were exhibited in their daily actions and approaches to education. These may be key traits and behaviours that are specifically required for teachers to become excellent at their craft.

\subsection{Beliefs}

Teachers demonstrated four primary beliefs in common. An authentic sense of self, in both personal and professional terms was essential. In addition, they experienced an implicit trust in their intuition, creativity and lateral thinking skills. Further to this, the teachers had a meaningful view of teaching as a vocation, and felt the need for "making a difference". Finally, they all had a great deal of passion for quality in life and work.

4.1.1. Authentic Self. Miller [9] writes, "perhaps the most important element in soulful learning is the teacher's soul. The teacher's soul must be nourished if the student's soul is to develop. There is nothing that our students desire from us more than our attention, our authentic presence". Two qualities that a soulful teacher can usually bring to the classroom are presence and caring. Presence arises from mindfulness where the teacher is capable of listening deeply.

Each of the teachers in this study had developed and nourished an authentic sense of self that did not depend on others' perceptions of them. There was a qualitative difference in how they acted as teachers and as people when they felt fully present. Teachers stated that when they felt like they were being true to themselves they sensed that their lessons and practices were much more engaging. This sense of 
mindfulness is a characteristic of good teaching. In each case, soul was demonstrated in different ways. In Mike's case, the authenticity of his coaching was one of his personal measures of excellence. "If I am not fully there, then I can't transmit the energy my kids need. They need to sense that I am at my best so they can be at their best" (Mike,Case Study \# 3, 2005). For Sarah, being authentic in the residential setting meant letting kids see her as a real person. Working with boarding students has its inherent risks, and she was fully aware that the best way to reach students was to be fully present with them. Jake demonstrated confidence and authenticity by staying true to his teaching style, and by letting students see him as a real person and not merely as a football coach. For Susan, mindfulness was shown in the daily care she exhibited and in her ability to really listen to students' personal concerns.

The teachers also expressed that students appeared to be alienated from developing a true and honest sense of self because they were trying to please so many people and get the right marks. Each of the teachers interpreted this as a cultural phenomenon. As teachers, they were true to themselves in order to model for students that they too should develop authenticity and an ability to question cultural norms. As Ferguson [6] notes, "the real alienation in our time is not from society but from self".

Developing an authentic sense of self may be something that takes time and experience. While these teachers all had between ten to thirty years of teaching experience, they also said that their personal life experience had carved them into the individuals they had become. There was not a clear line between who they were in the classroom and who they were as human beings. "Performing" in the sense that other disciplines put on a show temporarily or competitively is a different scenario than the one we witness in educational settings. Teachers perform in so many different roles during a single school day and for a longer time period than most performers in other domains. For teachers, performing means letting students see who we are, and this needs to occur at a slower, gentler pace than it may occur in other high performance activities.

4.1.2. Trust in Intuition.Each of these teachers expressed a very strong sense of their inner voice as teachers. They trusted their gut feelings and placed a high priority on intuition. In teaching situations, this may be a critical component for high performance. Because of the high degree of variability in any one class, teachers need to be able to react to unpredictable situations quickly and accurately. Very rarely do they encounter a consistent and conventional educational situation that is easy to replicate. Because they are dealing with so many adolescents, whose lives are unpredictable and full of emotional swings, teachers' respect for their own intuitive responses is the key to the climate in the classroom. As Claxton [5] observes, "teaching is a highly specific process but one which nevertheless has similarities with others involving the performance of complex and diverse skills in real time and in contexts that are unpredictable and constantly evolving".

The combination of variables and how well the teacher deals with them instantaneously both affect the quality of the learning moment. These teachers did not view intuitive choices as uncertain; they stated that they were merely choosing a different kind of certainty and trusting in an inner wisdom. Clearly, intuition is a valid source of knowing for excellent teachers. Ferguson [6] speaks about the type of inner knowledge this entails. Paradoxically, if we give up the need for certainty in terms of control and fixed answers, we are compensated by a different kind of certainty, a direction, not a fact. We begin to trust intuition, whole-brain knowing, what scientistphilosopher Michael Polanyi [15] termed "tacit knowing".

It is ironic that education has a long history of distrusting intuition. This may be a very unfortunate situation, since the teacher case studies in this research indicate that intuition is essential to excellent teaching. We have, as a culture, learned to distrust intuition and our teacher education programs must include intuition as an important reservoir of professional knowledge. Claxton [5] discusses the cultural value judgements placed on cognition as a higher order of knowing than aesthetics and intuition. He states "the distrust of intuition and the inability to see how and even perhaps why it could be incorporated into education reflect three hundred years of European cultural history. The Enlightenment picked out just this single way of knowing and, in raising it to a high art, implicitly ignored or disabled others: those that were not so clinical and cognitive and were instead more bodily, sensory, affective, mythic or aesthetic, in a word, intuitive." Intuition should be seen as a valid way of knowing for teachers. School leaders who respect this will be able to develop more high-performing teachers. Because of its holistic nature, intuitive teaching is an essential component of a healthy school environment. Respect for the influences of others, the community, and the physical, mental, spiritual and social aspects of work all add to the intuitive decision making of these excellent teachers. 
4.1.3. Teaching as Vocation. The values of the highperforming teachers in this study were internally based. It was clear that each had taken a path to teaching that was unique, but each of them believed that they were fully meant to be there. Teaching was not just a job with good summer holidays; they all saw it as what they were meant to be doing with their lives. They all felt, despite the inevitable frustrations of a career in education, that they were making a real difference. They also tried to role model this attitude for students and would agree with Postman [16] that "at its best, schooling can be about how to make a life, which is quite different from how to make a living". This certainty has created a sense of autonomy and confidence in their life choices and this sense appears to be critical in teacher excellence. Ferguson [6] concurs that "most importantly, when people become autonomous their values become internal. Their purchases and their choice of work begin to reflect their own authentic needs and desires rather than the values imposed on them by advertisers, family, peers, and media."

These teachers experienced frustration when the educational system did not support their values, or when they were forced to operate in any way that did not align with their inner values. Academic pressures for university entrance created frustration for them at times, due to the fact that they valued "real learning", whether or not it meant the student got accepted into the "right" university. This type of "real learning" may or may not be what students experience at the university level, however, these teachers all had a sense of what constituted high quality learning. In many cases, they spoke of application of the knowledge, the ability to apply learned knowledge in new situation, and the willingness to be curious about new ideas as examples of "real learning" (Jake, Case Study \# 2). In the case of two teacher participants, the excessive time demands were very frustrating. Busy work jobs that did not have deep meaning to them became tasks that were exercises in frustration. They chose to teach in a way that respected "voluntary simplicity", which has been referred to by Ferguson [6] as "a lifestyle in which one avoids clutter and focuses one's energies on what really matters. Voluntary simplicity is an attitude, not a budget: thoughtful consumption, resistance to artificially created needs, sensitivity to the limits of natural resources, a more human scale of living and working."

The obvious difficulty of operating most schools on the principles of voluntary simplicity is clear. Cultural pressures to define education in competitive terms of degrees and marks may be impeding the kind of creative, excellent and "real" teaching which the culture desperately needs. There is a distinct values shift in excellent teaching that is qualitatively different, and school leaders need to be able to recruit and train teachers who view their profession as a real vocation. Teachers who perceive their profession as a "calling" are more driven towards excellent performance in the classroom and on the playing fields.

4.1.4. Passion for Quality.Each of these teachers demonstrated a great passion for high quality. They had little tolerance for low level experiences, and they knew and had defined for themselves what good quality meant. "Quality" is a term that aligns itself well with excellent teaching. However, the difficulties in defining "Quality" mirror the challenges of defining "Excellence". Cultural, gender and demographic parameters must be taken into consideration.

The key point is this: for these teachers to perform at a high level, they had to stay true to their personal definition of quality in living and working. This definition had to have a high degree of congruence with the institution's definition of quality. Supports had to be in place to help teachers produce high quality work, and school leaders had to be open minded, flexible, and adaptable to ensure this happened. A great deal of resentment, anger, and frustration resulted when this support did not occur. This passion for quality and drive for excellence are mirrored in many high performers in other areas, and similar levels of frustration are evident when bureaucratic barriers impede the individual's drive towards the performance he/she desires.

Quality in the business sense is not what these teachers were referring to, and the trends in business towards Total Quality Management mentioned by Peters \& Waterman [13] appear to be product oriented and, thus, not useful in educational settings. These teachers were all very process oriented and measured their success over the long term. These teachers used themselves and each other to evaluate their professional expertise. A model such as Total Quality Management does not work in highperforming schools because, as Palmer [12] reveals, "we lack reliable methods for evaluating teaching. Second, good education is almost always more process than product. Third, good education may leave students deeply dissatisfied for a while. It can take years for a student to feel grateful to a teacher who introduces a dissatisfying truth." Clearly, attention to process and commitment to quality are two hallmarks of excellent teachers. School leaders must be prepared to invest in the long term and to have a variable definition of high quality teaching that aligns itself with the needs of the community in which the school resides. 


\subsection{Behaviours}

4.2.1. Healthy Lifestyle. Teachers in this study maintained a commitment to healthy living, and three of them stated that, when the components of health were not there due to stress or other outside influences, the quality of their teaching and lessons deteriorated. For Jake and Mike, exercise became an emotional outlet to release the stress of their jobs. Jake also had a role in designing fitness programs for other staff members who wanted to improve energy levels, decrease cholesterol or get back in shape. To escape the pressures of residence life, Sarah and Jake worked out at a local gym. Susan had a walking or recreational sport regime that contributed to her positive attitude to teaching. Health related practices had a direct impact on their abilities to perform well in their jobs. It is clear that a healthy lifestyle is a critical part of the foundation of excellent teaching.

As Langford and Carter [7] note,"the goal of educational excellence is certainly understandable, however, if tomorrow's scholars die prematurely from hypo-kinetic diseases their greatest contributions to society will never materialize. The ancient Greeks understood that the educational experience encompassed the development of mind, body, and spirit, with each deserving equal importance." For teachers to perform at high levels, good healthy practices are critical. In addition, the school must support and model good health practices, and give teachers time to take care of their bodies and minds in a way that suits them, while still fulfilling the demands of their jobs. Attention to preventive health practices could alleviate some of this stress related anxiety about teaching at a high level.

Each of the teachers in this study was both aware of and had dealt with some health concerns of students in the past. Their commitment to healthy learning was evident in the way they respected students' needs for physical activity, proper nutrition, and adequate sleep. Jake was encouraged by the development of the school's fitness and physiotherapy centre, and by the increasing availability of guidance counselors. He reiterated that "I think it's important that the kids see me out there sweating too; that way they know that being active is really part of my life" (Jake, Case Study \# 4, 2005). Ultimately, a school's firm commitment to student and staff health becomes part of the foundation for excellent teaching.

4.2.2. Personal Life. Maintaining a reasonable personal life outside the school is a challenge in the independent school setting. It was very clear, however, that each of these high-performing teachers made it a priority to step back from their work and protect their private time. In some cases, it was a hard lesson learned over time by those who had reached a level where they realized that they were no longer performing at their best. Orlick [11] reflects that "many people begin their careers believing that the harder you work, the better you will be. This holds true only to a point. Working so long and hard that you do not have time to recover physically or emotionally can work against you. Over time, your performance may decline rather than improve, which may make you think that you need to work even harder. Great performance requires quality rest. Highly committed people have to guard against overworking, which can cause a downward spiral of emotions and performance."

This may be a particularly large barrier to new teachers, who try to take on so much in order to impress their colleagues and school principal, or just to keep their jobs. This practice may impede their progress towards excellent teaching. The demands of the teaching profession are growing exponentially, and teachers are asked to be everything, including social workers, counselors, choreographers, coaches and more. The teachers in this study were no exception to this, however they did protect their personal time. This behaviour may be partly due to life experience, but it is also a factor which is common in excellent teachers.

Protecting their personal space required them to be very sure of their internal value system. It meant confronting the guilt that exists in many independent schools and the cultural affinity for doing more and more, and for working harder and faster to get ahead. Each of these teachers respected his/her personal pace and stepping back from their roles as teachers helped them to keep things in perspective. Finally, these teachers emphasized the positive aspects of their personal lives, and used these to enhance their professional performances. Orlick [11] states that "high quality living and performance are enhanced by making environments positive and uplifting, by finding opportunities within the situations we face and by embracing good qualities in ourselves and the people around us". Clearly, teaching at a high level requires mental and emotional breaks that can be enhanced by cultivating a strong and positive personal framework that is unrelated to the school and work environment.

4.2.3. Expertise in Content.The teachers in this study represented a variety of content areas including physical education, as they also taught smaller sections of science, guidance, and technology. Two of the teachers held leadership roles as Directors of Athletics and Director of Physical Education programs. Despite the areas of teaching, what they all 
had in common was a passionate commitment to increasing their expertise in their content area. It was not unusual to see them on the leading edge of current events, techniques, and topics that were incorporated into their lessons. Experts in the fields were often brought in to enrich classes. They appeared to never be satisfied with less than their best, and did not present themselves as "experts" to their students. Many studies have found that teachers with a higher degree of professional expertise were less susceptible to the stress loads than those teaching in content areas where they had less practical knowledge. Rean and Baranov [17] reveal that "expert teachers have a higher need for complete selfrealization. Teachers having a high level of pedagogical expertise are superior to teachers who have a low level of pedagogical expertise and this exerts a substantial influence on the level of teachers' stress tolerance." It is ironic that many first year teachers are placed in situations where numerous preparations are required, and many operate in areas of "leftover" courses that have to be taught. Teachers with the most experience usually teach the courses they are already comfortable with, and those with low levels of experience often teach the broadest spectrum of courses. This is a formula for preventing excellence. New teachers should only be given courses in which they have a good level of content competence, but in reality this is rarely the case.

In addition, the teachers in this study were not intimidated by students or other teachers who had appeared to show greater content knowledge in one area or another. The common values held by the excellent teachers in this study were as follows. First, that knowledge is not static; second, that expertise in any content area must respect the fact that we live in an information society; finally, that access to new knowledge and knowing how to apply in it novel situations are equally or more important than knowing a series of static facts.

In Mike's situation, his expertise did not arise from formal pedagogical training. This lack of training had a greater effect in his initial years of teaching. However, he had a mentor relationship at the beginning of his career with a formally trained senior teacher at the same school. This enabled him to learn and gain in-service training while teaching and coaching. In a sense, it would seem he started his teacher education by taking a yearlong apprenticeship practicum with the senior teacher at the school. This brings forward the question of the relevant importance of theory of education classes versus practical experience. Both are deemed to be an important part of the teacher education process. Mike's experience and development towards becoming a teacher who was identified as "excellent" based on Orlick's [10] parameters, was based almost entirely on practical experience in the field. This raises some important issues. In particular, it introduces the question of how important is each component of the teacher education process. Mike also had a strong background in his subject area from both personal experience as a student and athlete. However, this contradicts Susan's views that expertise as an athlete does not necessarily transfer to expertise as a teacher. Mike felt that his weakest area lay in being up to date of strategies for assessment and evaluation. The gap he felt was remedied by regular in-service training.

4.2.4. Risk Taking and Valuing Mistakes.High performers in many professional areas value the importance of taking well calculated risks. They ensure that they are as well prepared as possible, and use their expertise to assess possible outcomes, prior to venturing into new, uncharted territory. They are not intimidated by new challenges, and they look forward to finding creative solutions to problems. In this way, expert teachers become highly skilled at functioning in new situations [3].

They are continually practicing the techniques associated with expert thinking, including the ability to go beyond practiced habits or routines to develop new ways of framing problems. They operate with confidence and examine all of the facts, realizing that the fact they may need may be quietly sitting adjacent to the one a non-expert might have ignored as unimportant [14]. Each of the participants in this study discussed this type of behaviour and mentioned situations that they had to resolve using creative or innovative solutions. In addition, they were able to remain calm throughout the process. Maintaining an ability to see the larger picture when under emotional stress is an advantage when taking a risk. In venues beyond education, this is clear in the performance of astronauts in potentially life threatening situations [11]. It is the combination of being highly prepared and having the affective control in the moment that allows high-performing teachers to take risks and accept making errors. Instead of fearing mistakes, these teachers looked for the learning in the situation and often found valuable knowledge in the process.

\section{Conclusions}

These case studies have produced a snapshot of teachers who were performing at high levels; three of them stated in the interviews that they had questioned how long they could handle working at such an intense pace. The nature of the teaching moments which they chose to discuss demonstrates the high 
level of emotional involvement that they felt for their students and their work. This level of passion for the profession may be a prerequisite for excellent teaching, but it can also be a precursor to burnout.

School leaders must be aware that their best teachers, or those with the potential to be their best, are also at high risk for stress and burnout. They need to be coached in terms of the strengths shown by the participants in this study. Maintaining a personal life, keeping a healthy lifestyle, balancing commitment to work and to self are all habits that must be nurtured in young teachers to prevent burnout. The path to excellence across professions lies dangerously close to the path to burnout. Excellence requires an emotional, intellectual and spiritual intensity on the part of the individual which must be managed and balanced with care.

\section{References}

[1] A. Anderson and N. Piran, "Health Promoting Schools", CAHPERD Journal, (Spring), 1999, pp. 10-15.

[2] S. Barbour and T. Orlick, "Mental skills of national hockey league players", Journal of Excellence, (January), 1998, pp. 60-80.

[3] Bereiter, C. and M. Scardamalia, Surpassing Ourselves, Open Court Publishing, .Peru IL, 1993.

[4] J. Cibulka and M. Nakayama, "Practitioners' guide to learning communities: the creation of high-performance schools through organizational and individual learning", (ERIC Document Reproduction Service No. ED 449141) 2000.

[5]Claxton. G. (1997). Hare Brained and Tortoise Mind. London, ON: Fourth Estate.

[6] Ferguson, M. The Aquarian Conspiracy. St. Martin's Press, New York, NY. 1980.

[7] G. Langford \& L. Carter (2003). Academic excellence must include physical education. The Physical Educator, 60(1), 28-33.

[8] Merriam, S. (1998). Qualitative Research and Case Study Applications in Education. San Francisco, CA: Jossey-Bass.

[9] Miller, J. (2000). Education and the Soul: Toward a Spiritual Curriculum. New York, NY: State University of New York Press.

[10] T. Orlick, (1992).The applied side: the psychology of personal excellence, Performance

Enhancement. (1), 1992, pp. 109-122.

[11] Orlick, T. (1998). Embracing Your Potential. Ottawa, ON: Human Kinetics.
[12]Palmer, P. J. (1998). The Courage to Teach: Exploring the Inner Landscape of a Teacher's Life. San Francisco, CA: Jossey-Bass.

[13] Peters, T. and R. Waterman, In Search of Excellence. Harper Books, New York, NY, 2004.

[14] Pirsig, R., Zen and the Art of Motorcycle Maintenance. Bantam Books, New York, NY, 1974.

[15] Polanyi, M. (1967). The Tacit Dimension. New York, NY: Doubleday.

[16]Postman, N. (1994). The Disappearance of Childhood. New York, NY: Random House.

[17] A. Rean \& A. Baranov (1998). Factors in teachers' tolerance of stress. Russian Education and Society, 40(5), $52-68$.

[18] C. Talbot and T. Orlick, "The essence of excellence: mental skills of top classical musicians" Journal of Excellence, (January), 1998, pp. 82-93.

[19] C. Tribble and D. Newburg, "Learning to fly: teaching mental strategies to future surgeons", Journal of Excellence (January) 1998, pp. 8-18. 